\title{
A MARC BASED SDI SERVICE
}

Kenneth John BIERMAN: Data Processing Coordinator, Oklahoma Department of Libraries; and Betty Jean BLUE: Programmer, Information and Management Services Division, State Board of Public Affairs, Oklahoma City, Oklahoma.

An operating SDI service utilizes the weekly MARC II tapes distributed by the Library of Congress. The history, creation, operation, uses, advantages, disadvantages, cost and future plans for the SDI service are discussed, and flow charts (system and detail) and sample output given.

\section{INTRODUCTION}

SDI (Selective Dissemination of Information) is the distribution of new information to individuals or groups according to their expressed interests. SDI as a service of libraries is not a new concept, for libraries have been providing such specialized current awareness services for years both formally and informally in such ways as routing proof slips to interested persons, departments, etc. Such services have been provided most commonly in special libraries, but are not uncommon in public and academic libraries as well (1). "Although the practice of SDI is not new, its application in libraries has been generally irregular, informal, and very limited - depending variously on the memory, willingness and free time of the librarian and contingent on the desire and ability of the patron to make his interest known" (2).

With the interest in library applications of data processing has come 
an interest in automated SDI services. "All computer based SDI systems work on the same principle and include two basic elements: subject interest profiles for the users and a machine readable file of indexed bibliographic records of current materials." (3) The Annual Review of Information Science, Volume 4, presents a summary of many different types of SDI systems (4) as well as an excellent bibliography (5). Additional recent automated SDI services are described in the literature (6-12).

The purpose of this article is to describe an operating MARC-based SDI system, the environment within which it operates, and some of the thinking which led to its creation.

\section{BACKGROUND INFORMATION}

The Oklahoma Department of Libraries is the designated State Library Agency in Oklahoma. As such it has two primary statutory responsibilities: 1) provision of library services to State Government, including the Executive, Legislative and Judicial Branches of Government, and the agencies of State Government and 2) state-wide responsibility for total library development, including the development of multi-county library systems. The Department provides a great variety of library services to fulfill these functions, one of which is the maintenance of a collection of materials with three subject specialty areas: 1 ) law (primarily of use to the Judicial and Legislative Branches), 2) political science (primarily of use to the Executive and Legislative Branches), and 3) library science (primarily of use to the Department's own staff and the librarians throughout the State). In addition, a general collection and a general reference collection are maintained primarily for use by the Executive and Legislative Branches of State Government and as back-up and supportive collections to the libraries throughout the State.

With the beginning of the MARC Distribution Service March 29, 1969, the Department implemented a service for other libraries around the State by creating and maintaining a MARC Data Base for the use of all libraries within the State (13). After the data base had been created and was working satisfactorily, the Department considered what it could do with MARC to help its own operation. The five following paragraphs discuss projects suggested and considered.

The first was design and implementation of the original input of a selected portion of the collection (the law collection, for example) in MARC format. The project would be a beginning of putting the entire collection in MARC format and would yield interim useful products as well (a book catalog, for example). However, it was decided that this project would be premature for two reasons. If retrospective conversion were going to be done nationally (14), it would be foolish for the Department to duplicate the work at the local level; and before the Department should expend money putting material into MARC format, it should demonstrate the 
usefulness of MARC with the already existing records being distributed by the Library of Congress.

A second project considered was design and implementation of conversion of the storage of the MARC data base from the sequential (tape) system (13) to a direct-access system (disk, for example). Certainly from the standpoint of economic use of the data base such conversion is desirable, and for providing multiple access points to the data base (author, title, subject, etc.) it is essential. It was decided, however, that before additional funds and energy should be expended to improve the storage and retrieval of MARC records, the usefulness of the presently available individual records themselves should be demonstrated. Direct access storage and retrieval was deferred until the completion of the SDI system. Work has recently begun on the direct access project (15).

Design and implementation of an acquisitions module for the Department was considered because the Department was preparing to re-design its acquisition system. However, to have a meaningful automated MARCbased acquisitions system it would be necessary to search the data base by a number of entry points (author, title, etc.), which would require the direct access system described above.

A fourth project considered was design and implementation of a catalog card set and processing aids (label, etc.) production module for the Department. Because the Department does centralized processing for the library systems throughout the State, the Processing Center is a critical area within the library; therefore, this alternative had the most immediate appeal. It was decided that the Department was not financially prepared to undertake so ambitious a project yet. It was felt that a less ambitious project should be undertaken first to gain knowledge and experience which would be essential in a successful catalog card and processing aids production system.

The project ultimately selected was design and implementation of a subject current-awareness service based upon the weekly MARC tapes. The service would be immediately useful, both to the Department and its clientele; was not dependent upon the maintenance of a large data base; and could be set up and operated quickly and economically. Further, the experience gained in manipulating the MARC records in the print portion of an SDI system would be valuable experience for manipulating the MARC records for printing catalog cards and processing aids at a later date.

\section{OVERVIEW OF THE SDI SYSTEM}

First, the subject interests of a particular user (perhaps an individual, but more likely a State agency) are profiled in Dewey and/or L.C. classification numbers by a reference librarian from the Department. For example, the Library School could use a listing of MARC records on each weekly tape dealing with library science. Table 1 is a library science profile. 
The Dewey and LC classification numbers of each MARC record on a tape are compared with the profiled Dewey and LC classification numbers.

Table 1. Library Science Profile.

\section{Subject}

Library Science

Manuscripts \& rare books

Ethics of librarianship

Library manpower

Library study techniques

Audio visual instruction

Films in adult education

Printing \& binding

Bookselling

Management of libraries

City planning \& libraries

Architecture \& libraries

Book illustration

Motion pictures
Dewey Numbers

020-029

090-099

174.902

331.76102

371.30

371.33

374.27

655

658.809655

658.9102

711.57

727.8

741.64

791.43

When either the Dewey or LC number matches, that record is pulled from the MARC tape and copied onto a detail tape. After the entire MARC tape has been searched, the detail tape is rewound and the selected records are printed.

\section{DESCRIPTION OF THE SDI PROGRAMS}

The SDI system consists of two programs: the first, ODL- $\emptyset 7$, pulls the appropriate records from a MARC tape, and the second, ODL- $\emptyset 7 \mathrm{X}$, prints these records in a readable form and appropriate sequence. Figure 1 is a system flow chart.

\section{ODL-@7 Program}

Inputs are 1) a control card giving program identification and date; 2) header cards containing list codes and headers. (The list code is a one-character code that uniquely identifies the list, e.g., "Z" for library science; the header will appear on each page of output, e.g., "LIBRARY SCIENCE" for the library science list.); 3) classification number cards, which contain the proper list code, a selector code ("D" for Dewey and " $\mathrm{C}$ " for Library of Congress), and the LC or Dewey classification number or range of numbers to be selected; and 4) the MARC tape to be searched.

Outputs are: 1) a header tape containing all the information from the header cards and the date, and 2) a detail tape containing all selected records with a list code for each record. 


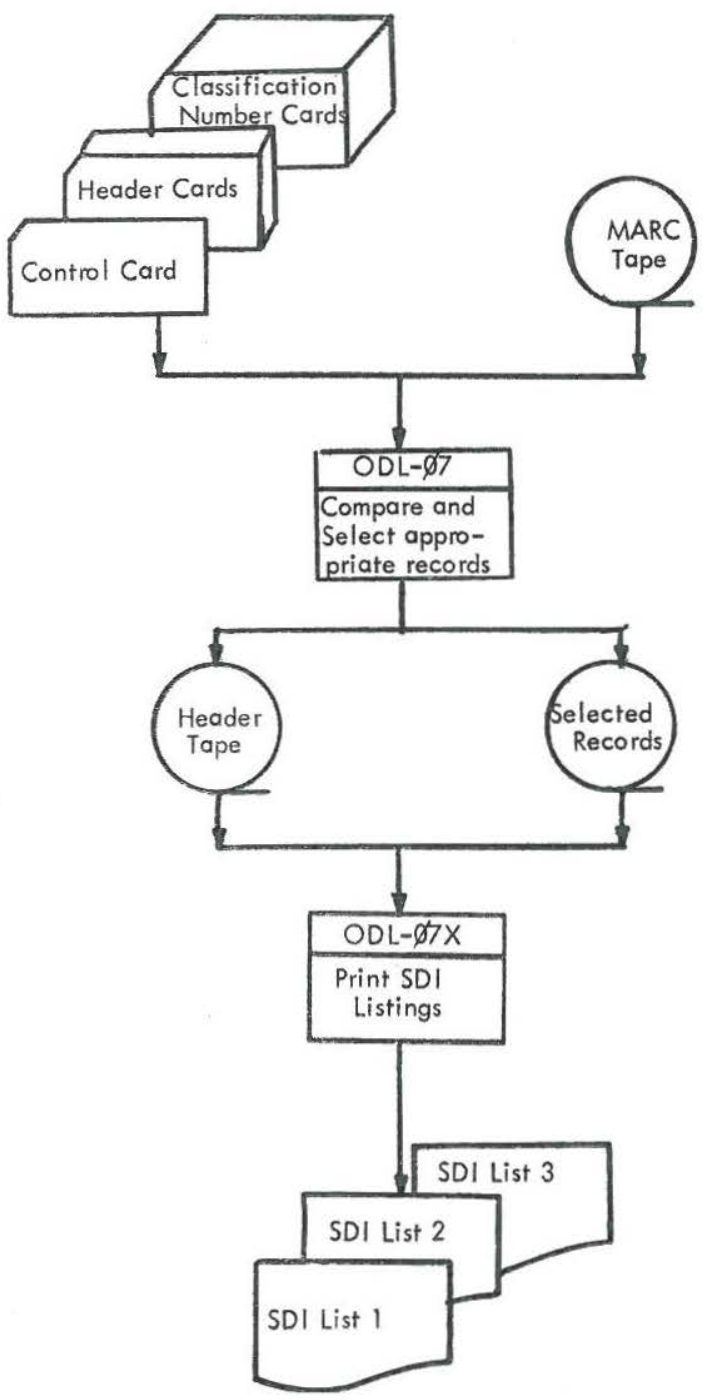

Fig. 1. SDI System Flow Chart.

Figure 2 is a detail flow chart for ODL- $\emptyset 7$. The control and header cards are the first to be read. A header table is constructed for editing and records are written on the header tape. The classification number cards are then read. These cards are edited first for such errors as invalid list code (for each list code on a classification number card, there must be a corresponding header record), invalid selector code (must be "C" for LC or "D" for Dewey), and invalid characters in the LC or Dewey numbers (Dewey may not contain any alphabetic characters and the only valid special characters for Dewey are the period and dash; the first 


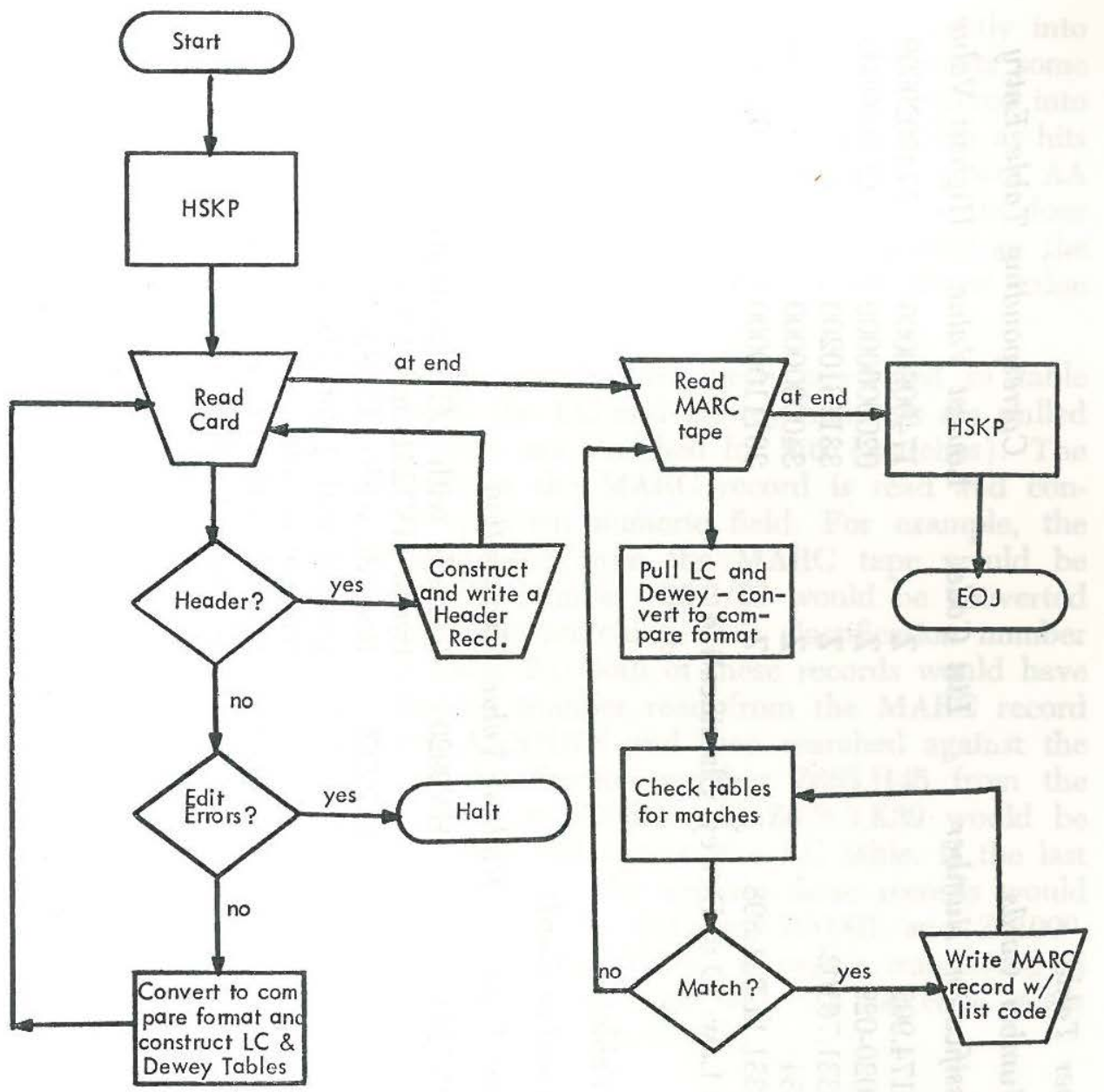

Fig. 2. ODL- 07 Detail Flow Chart.

character of LC must be alphabetic). If the classification cards pass edits, they are used to construct LC and/or Dewey entries. Each table entry consists of three items: the lowest acceptable value, the highest acceptable value, and the list code.

Dewey classification numbers can be input into the system without reformatting and are converted by the program to table entries. Table 2 presents some Dewey numbers as they might be keypunched and input into the system and the corresponding table entries which would be created. Dewey numbers are converted from the free form to a fixed-length 10-position all-numeric form.

LC classification numbers are more difficult. These cannot be entered into the system without reformatting as can the Dewey numbers; rather, 
Table 2. Dewey Classification Number Table

Keypunched Classification Number Cards

List Code Selector Code Classification Number

$\begin{array}{ll}\mathrm{Z} & \mathrm{D} \\ \mathrm{Z} & \mathrm{D} \\ \mathrm{Z} & \mathrm{D} \\ \mathrm{L} & \mathrm{D} \\ \mathrm{L} & \mathrm{D}\end{array}$

D $\quad 174.902$

D $\quad 020-029$

D $\quad 331.76102$

D 34

KEY: $\mathrm{Z}=$ Library Science; $\mathrm{L}=$ Law; $\mathrm{D}=$ Dewey Classification
Corresponding Table Entry

List Code

Lowest Value

Highest Value

1749020000

0200000000

3317610200

3400000000

3311100000

Table 3. LC Classification Number Table

Keypunched Classification Number Cards

\begin{tabular}{|c|c|c|c|c|}
\hline List Code & Selector Code & Lowest Value & Highest Value & Explanation \\
\hline $\mathrm{P}$ & C & HV7231 & HV9920 & $\begin{array}{l}\text { Records with LC classification number be- } \\
\text { tween HV7231 and HV9920 will be hits. }\end{array}$ \\
\hline $\mathrm{P}$ & $\mathrm{C}$ & J00000 & JKZZZZ & $\begin{array}{l}\text { Records with LC classification number be- } \\
\text { ginning with J and JA-JK will be hits; JL-JZ } \\
\text { will not be hits. }\end{array}$ \\
\hline $\mathrm{L}$ & C & K00000 & KZZZZZ & $\begin{array}{l}\text { Records with LC classification number be- } \\
\text { ginning with K (including KA-KZ) will be } \\
\text { hits. }\end{array}$ \\
\hline $\mathrm{Z}$ & $\mathrm{C}$ & Z00001 & Z01000 & $\begin{array}{l}\text { Records with LC classification number be- } \\
\text { tween } \mathrm{Zl} \text { and } \mathrm{Z} 1000 \text { will be hits. }\end{array}$ \\
\hline
\end{tabular}

KEY: Z = Library Science; L = Law; $\mathrm{P}=$ Political Science; $\mathrm{C}=\mathrm{LC}$ Classification 
low and high values are entered into the system and put directly into the LC table for searching of the MARC tape. Table 3 presents some LC classification numbers as they might be keypunched and entered into the system and a brief explanation of what records will be pulled as hits (matches). LC table entries are in the form of AANNNN where AA stands for the two possible initial letters and NNNN stands for the four numbers following the initial letter(s) and immediately preceding the first decimal point or next alphabetic character. Zero is the lowest value and $\mathrm{Z}$ is the highest.

After all classification number cards have been converted to table entries, the MARC tape is read, the LC and Dewey numbers are pulled from each record, and both tables are searched for hits (matches). The Dewey classification number from the MARC record is read and converted into a fixed-length 10-position numeric field. For example, the classification number 020/.6234/5456 from the MARC tape would be converted to 0206234545 and the number $025.3 / 02$ would be converted to 0253020000 before Dewey table searching. If a classification number card had been 020-029 (see Table 2), both of these records would have been a hit. The LC classification number read from the MARC record is first converted to the form AANNNN and then searched against the LC table. For example, the classification number Z665.H45 from the MARC tape would be converted to Z00665 and Z678.3.K39 would be converted to Z00678 and then searched against the LC table. If the last entry in Table 3 had been input into the system, these records would both be hits, as their LC numbers lie between Z00001 and Z01000. If a match is found in either table, the MARC record is transferred in the original MARC format to the output tape with the list code. After ODL- $\emptyset 7$ is completed, control passes to ODL- $\emptyset 7 \mathrm{X}$.

\section{$O D L-\emptyset 7 X$ Program}

Inputs are the header tape from the previous run and the detail tape containing the selected records from the previous (ODL-07) run. Outputs are the SDI listings by subject areas (list code). Figure 3 is a detail flow chart for ODL- $\emptyset 7 \mathrm{X}$.

The first record is read from the header tape and the detail tape is then searched for matching list codes. When a match is found, the MARC record is formatted and printed. When the entire tape has been searched, the next header is read, the detail tape is rewound and the process is repeated. This continues until all header and detail records have been matched and printed. The result is a series of SDI lists, each in LC card number sequence. See Figure 4 for a sample of two printed records from a library science list. Presently, the weekly lists are being printed on two-up, three-part, perforated teletype size $\left(81 / 2^{\prime \prime} \times 51 / 2^{\prime \prime}\right)$ paper, one record (SDI notice) to each separable form. 


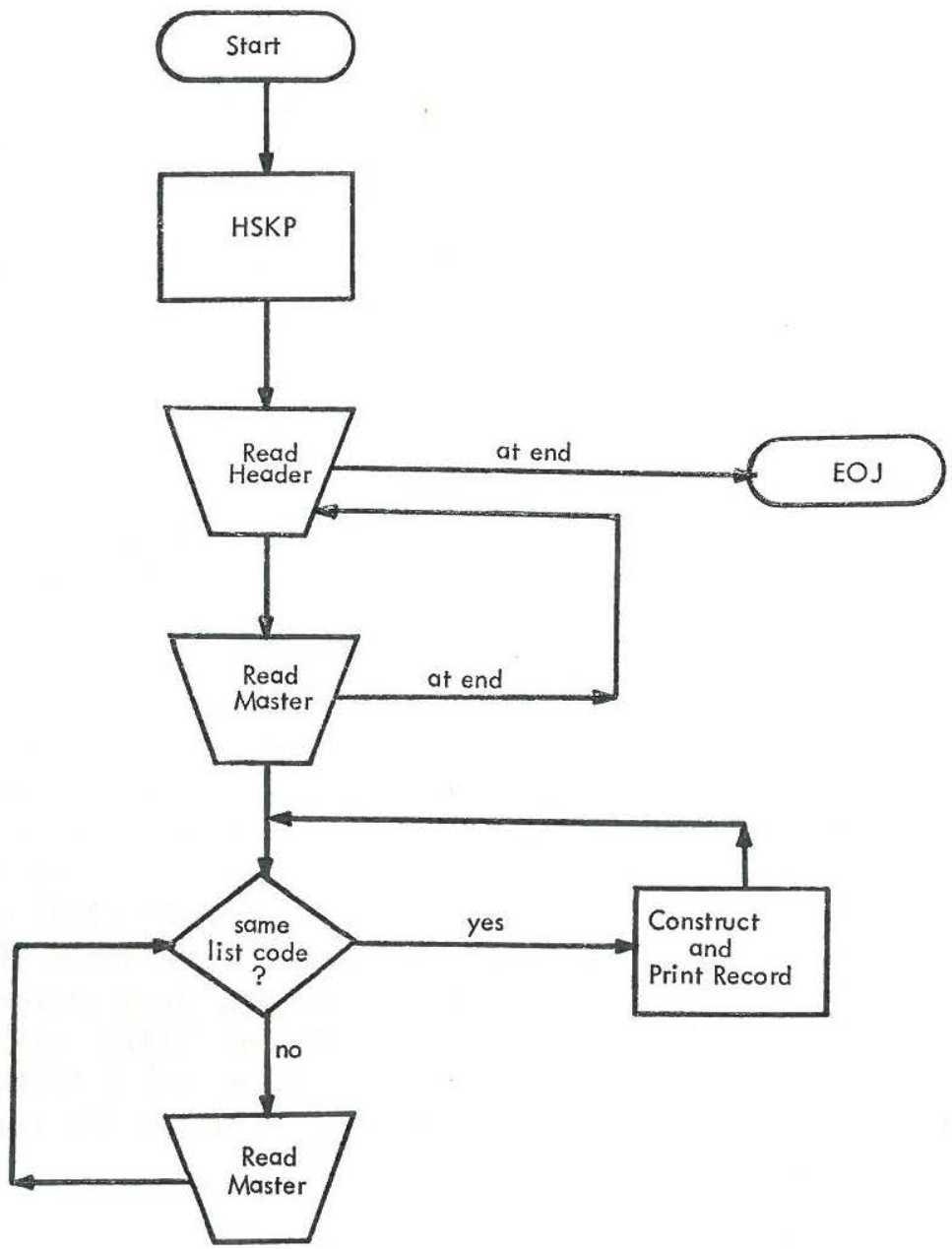

Fig. 3. ODL- $\$ 7 X$ Detail Flow Chart.

\section{DISCUSSION}

The SDI system was written with flexibility as one of the main considerations. Dewey classification number cards in almost any format can be machine converted to the intended table entry. Both ranges and individual classification numbers are allowed. Any number of Dewey and LC entries and any number of lists can be handled simultaneously, the only limit being core size. The selection tables, not being built into the programs, can be changed at any time, weekly if desired.

The print format generally follows traditional catalog card arrangement, the major difference being that each subject heading and added entry appears on a new line and is not numbered. The print program can be easily adapted to any conversion table desired; delimiters, field terminators, etc. are referred to symbolically. There is an optional feature which allows 
09/03/70 LIBRARY SCIENCE

STEVENS, MARY ELIZABETH.

AUTCMATIC INDEXING, A STATE=CF=THE-ART REPORT. REISSUED

WITH ADOITIONS AND CCRRECTICNS. WASHINGTON, U.S. NATIONAL

BUREAU CF STANCARDS, FOR SALE BY THE SUPT. OF DCCS• U.S.

ECVT. PRINT. CFF., 1970.

VI, 290 P. $26 \mathrm{CM}, 2.25$

(NATICNAL BUREAU CF STANDAROS NONOGRAPH 91 )

'A UNITED. STATES CEPARTMENT OF COMHERCE PUBlication.INCLUDES PIBLICGRAPHIES.

AUTCMATIC INDEXING.

l.S. NATICNAL BUREAU CF STANDARDS. MCNOGRAPH 91

$6 C 100.4556$ NC. $91,197 \mathrm{C} \quad 029.5$

$73=607239$

MARC - OKLAHOMA

Orlahoma Department of ligraries SDi User Information Service

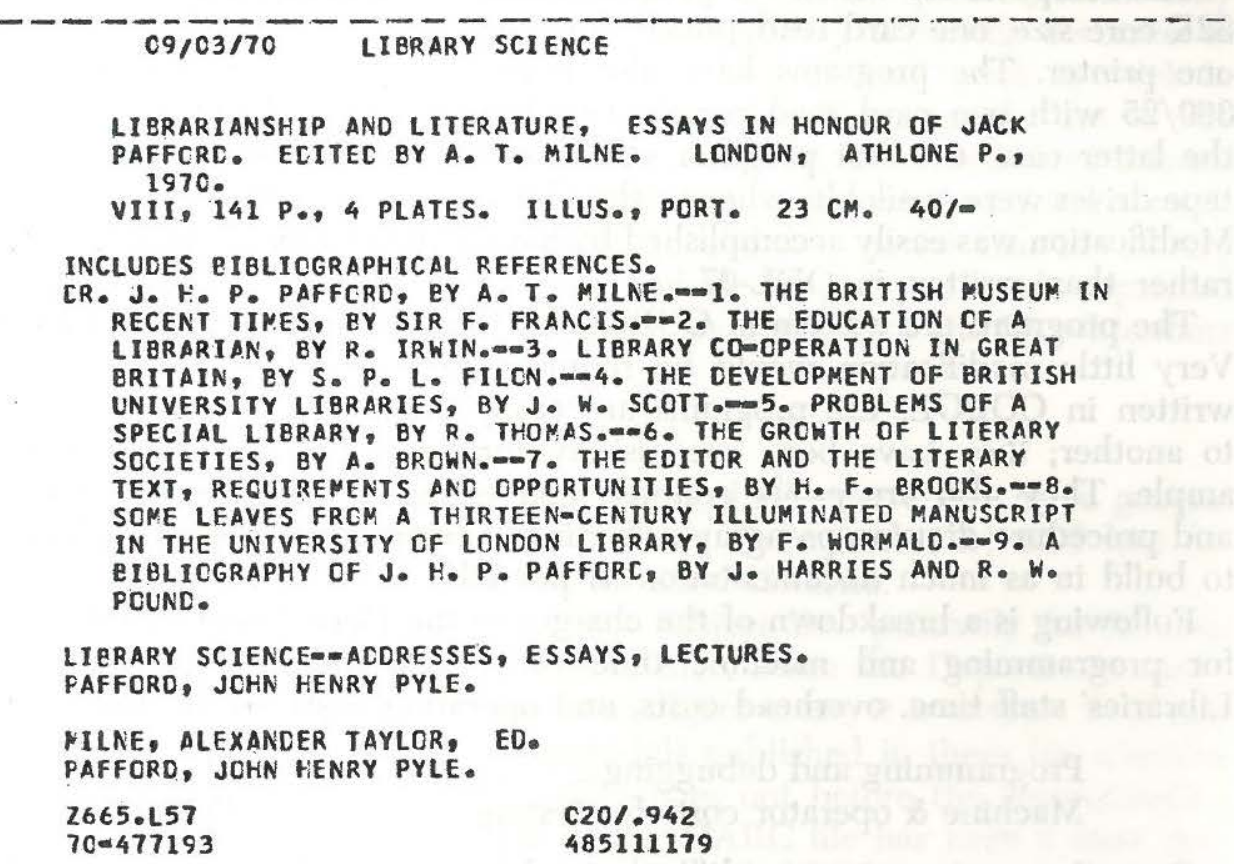

marc - Oklahoma Oklahoma Department of Libraries SDI User Imformation Service

Fig. 4. Sample SDI Notices. 
any character or characters to be deleted and the resulting gap closed; this is desirable for diacriticals until better techniques for handling them are devised. Both line and page length are referred to symbolically and can be easily changed to fit any form desired. Line spacing and indentation are built into the present program, but even these can be changed.

The major disadvantage of the SDI system as it now exists is that it allows selection by classification numbers only. Unlike the MARC I experimental SDI system at Indiana University (16), which allowed for selection by weighted terms (both classification number and subject heading), this system allows for classification number selection only. Programming difficulties, expense, and the necessity for additional processing time inhibit searching on subject headings. For selection of detailed subjects, subject heading searching is essential; however, for making subject searches in subject areas classification number searching seems more expedient, as it would be difficult to determine, and expensive to input, all of the subject headings for the field of law, for example. Ideally, a MARC-based SDI system would be able to provide selection based on classification numbers and/or subject descriptors.

\section{COMPUTER, LANGUAGE AND COST}

The computer for which the programs were written was an IBM $360 / 30$, $32 \mathrm{~K}$ core size, one card read/punch, four tape drives, two disk drives and one printer. The programs have also been successfully run on an IBM $360 / 25$ with one card read/punch, two tape drives and one printer. In the latter case, the first program was modified slightly because only two tape drives were available, whereas the SDI system normally requires three. Modification was easily accomplished by having the header records punched rather than written in ODL- $\emptyset 7$.

The programs are written in COBOL for the 360, operating under DOS. Very little modification would be required to operate under OS. Being written in COBOL, the programs are easily adapted from one machine to another; they have been successfully run on a RCA Spectra, for example. They also are easily adapted and changed, the symbolic names and procedure division paragraph headings having been carefully selected to build in as much documentation as possible.

Following is a breakdown of the charges to the Department of Libraries for programming and machine time for development; Department of Libraries' staff time, overhead costs, and operating costs are not included.

$$
\begin{array}{lr}
\text { Programming and debugging } & \$ 2,941.00 \\
\text { Machine \& operator costs for testing } & 452.00
\end{array}
$$

Operating costs are more difficult to determine and nearly impossible to evaluate meaningfully. The total amount of computer time required (and therefore the major cost) is primarily a function of the number of records on the MARC tape being searched and the number of selected 
and printed records. If the MARC tape contains 1,200 records, it takes about twelve minutes (clock time) of computer time (IBM 360/30, 32K) to select the desired records (ODL- $\emptyset 7$ ). As the total of classification numbers being searched increases (that is, as the Dewey and LC tables grow), the computer time for selection does not appear to increase significantly. The print program (ODL- $\$ 7 \mathrm{X}$ ) is directly a function of the number of lists being produced (the number of times the detail tape must be rewound and re-read) and the total number of records being printed. As an example, if six different lists are being produced and a total of 375 records are being printed out, the computer time is 25 minutes. Therefore, producing six weekly lists with an average of 62 records for each list takes approximately 37 minutes (clock time) each week. At the rate of $\$ 60.00$ an hour, this is $\$ 37.00$, or approximately $10 \mathrm{c}$ per record selected and SDI notice printed.

Table 4 presents a detailed analysis of five weekly runs. The total computer time is the number of minutes which were charged to the Department of Libraries by the computer center. Since the Department is charged one dollar per minute, this is also the dollar cost to the Department for computer and operator costs for that weekly run. Unfortunately, the total time given includes time for set-up and other factors. Therefore, meaningful patterns are difficult to discern, as one week it may take several minutes longer to get the forms inserted and lined up in the printer, forms may break another week, etc. The remainder of Table 4 is exactly accurate. It is interesting to note how much variance there is from week to week in the number of SDI notices for each subject list. For example, out of 889 MARC records on the MARC tape run on July 23,16 were library science titles. However, the MARC tape run on August 6 contained 1,201 records but only 12 were library science titles. In addition, notice that the library science list was reprinted seven times, and for the last two weeks reprinted five times, to get the total number of copies needed for the 25 subscribers to the list.

\section{CURRENT USES}

The uses to which the system is presently being put are in three general areas: 1) SDI lists for internal use of the Department, 2) SDI lists for State Government, and 3) SDI lists for other libraries.

The Department currently produces subject lists primarily for its own use in the areas of law and political science. Since the Department maintains specialty collections in these two subject areas, it is anxious to obtain the most current information on materials published in them for selection purposes. Because the MARC record comes out before the corresponding proof slip is distributed (17), use of the MARC file has been a most successful means of obtaining complete and verified bibliographic information for the purpose of ordering new books. In addition, complete LC cataloging information is available should the proof not have arrived at the time the book is received. Because the lists are currently being printed on three- 
Table 4. Sample Run Times and List Lengths.

\begin{tabular}{|c|c|c|c|c|c|c|c|c|c|c|c|c|c|c|c|c|}
\hline $\begin{array}{l}\text { Date of } \\
\text { Computer } \\
\text { Run }\end{array}$ & $\begin{array}{l}\text { lotal } \\
\text { Computer } \\
\text { Time } \\
\text { (Minutes) } \\
\end{array}$ & $\begin{array}{l}\text { Input Count } \\
\text { (Total num- } \\
\text { ber of re- } \\
\text { cords on } \\
\text { MARC tape) } \\
\end{array}$ & $\begin{array}{l}\text { Tape-Out } \\
\text { Count } \\
\text { (Total num- } \\
\text { ber of re- } \\
\text { cords copied } \\
\text { in ODL- }-67) \\
\end{array}$ & \begin{tabular}{l|} 
Print-out \\
Count \\
(Total num- \\
ber of SDI \\
Notices \\
printed in \\
ODL-Ø7X) \\
\end{tabular} & $\begin{array}{l}\text { Total } \\
\text { Number } \\
\text { of Lists } \\
\end{array}$ & 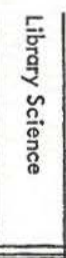 & 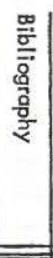 & 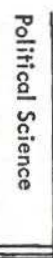 & 率 & 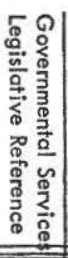 & 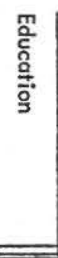 & 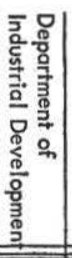 & 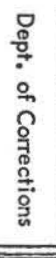 & 言 & 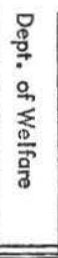 & \\
\hline \multirow{3}{*}{ July 9} & \multirow{3}{*}{65} & \multirow{3}{*}{1,467} & & & 15 & 7 & 1 & 1 & 1 & 1 & 1 & 1 & 1 & 1 & - & Numbe \\
\hline & & & 525 & & & 39 & $\frac{36}{36}$ & 87 & 75 & $\frac{92}{0^{2}}$ & 118 & $\frac{22}{3 n}$ & 15 & 41 & -- & ARC Records Selected \\
\hline & & & & 759 & & 273 & 36 & 87 & 75 & 92 & 718 & 22 & 15 & 41 & -- & Number of SDI Notices Printed \\
\hline \multirow[b]{2}{*}{ July 16} & \multirow[b]{2}{*}{57} & \multirow[b]{2}{*}{1,118} & & & 15 & 7 & 1 & 1 & 1 & 1 & 1 & 1 & 1 & 1 & $\ldots$ & Number of Print Runs \\
\hline & & & 456 & & & $\frac{24}{168}$ & $\frac{30}{30}$ & $\frac{76}{76}$ & $\frac{71}{71}$ & $\frac{83}{92}$ & 100 & $\frac{20}{20}$ & $\frac{8}{8}$ & $\frac{44}{44}$ & 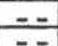 & $\begin{array}{l}\text { Number of MARC Records Selected } \\
\text { Number of SDI Notices Printed }\end{array}$ \\
\hline \multirow{3}{*}{ July 23} & \multirow{3}{*}{49} & \multirow{3}{*}{889} & & & 16 & $\frac{10}{7}$ & $\frac{11}{1}$ & 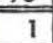 & 1 & 1 & 1 & $\frac{21}{1}$ & 1 & $\overline{1}$ & 1 & Number of Print Runs \\
\hline & & & $3 \pi 7$ & & & 16 & 16 & 71 & 60 & 65 & 73 & 21 & 5 & 34 & 16 & Number of MARC Records Selected \\
\hline & & & & 473 & & 112 & 16 & 71 & 60 & 65 & 73 & 21 & 5 & 34 & 16 & Number of SDI Notices Printed \\
\hline \multirow{3}{*}{ July 30} & \multirow{3}{*}{56} & \multirow{3}{*}{1,078} & & & 14 & 5 & 1 & 1 & 1 & 1 & 1 & 1 & 1 & 1 & 1 & Number of Print Runs \\
\hline & & & 437 & & & 23 & 32 & 57 & 61 & 80 & 89 & 29 & 11 & 38 & 17 & Number of MARC Records Selected \\
\hline & & & & 529 & & 115 & 32 & 57 & 61 & 80 & 89 & 29 & 11 & 38 & 17 & Number of SDI Notices Printed \\
\hline \multirow[b]{2}{*}{ August 6} & \multirow[b]{2}{*}{60} & \multirow[b]{2}{*}{1,201} & & & 14 & 5 & 1 & 1 & 1 & 1 & 1 & 1 & 1 & 1 & 1 & Number of Print Runs \\
\hline & & & 543 & & & $\frac{12}{60}$ & $\frac{23}{23}$ & $\frac{103}{103}$ & 80 & $\frac{113}{113}$ & $\frac{106}{106}$ & $\frac{31}{31}$ & 11 & $\frac{42}{42}$ & $\frac{22}{22}$ & Number of MARC Records Selected \\
\hline
\end{tabular}


part teletype paper, one record per sheet, it is easy to separate the record to be ordered and send one copy to acquisitions, retaining one copy for the files, and sending one to the interested individual in State government with a note that the book is on order.

The Department also produces a special list of many different subjects which are of interest to the Legislature for the Legislative Reference Division of the Governmental Services Branch. The Legislative Reference Division can then order particularly useful materials quickly and route a copy of the SDI printout to the interested legislator or legislative committee.

The Department has prepared profiles of the State agencies having a large planning and research role. Lists are prepared weekly for the Department of Education, Department of Corrections, Department of Vocational-Technical Education, Department of Welfare, Industrial Development Commission, Department of Highways, and several small agencies, and are sent to the person responsible for planning and research within the department. He can then request books from the lists by returning one copy of the SDI notice to the Department of Libraries with a note to order, retaining the other copy for his files or routing it to a researcher particularly interested in the subject.

Certain lists are being produced and shared with libraries around the State. The law and political science lists are being sent to two law schools in Oklahoma. The library science and bibliography lists are being sent to the Library School and the two largest public library systems, as well as the two State universities. Over 25 libraries outside Oklahoma are receiving weekly library science, political science or law lists (18). A cooperative acquisitions program is evolving whereby certain libraries agree to specialize in certain subject areas so that every subject area would be covered by one library for specialized materials not needed by all libraries. Currently, the program involves the two major public libraries and the Department of Libraries wherein the State Teletype network (OTIS) is used to transmit rapidly information on expensive materials for cooperative acquisitions. Selected lists in the specialized subject areas can be produced each week for each of the cooperating libraries to aid them in their selection, acquisition and cataloging of the materials.

The uses currently being made have excited the imagination of many people, both within and without the Department of Libraries. A great deal has been accomplished since the system became operational early in February 1970; however, the possibilities have barely been identified. As mentioned above, one can envision this being the foundation of a cooperative acquisitions program. Such a system could form a node of library service to business and industry; currently, some thought is being given to producing weekly lists of materials in automation and computer science (systems analysis, etc.) both for the many State agencies which have automated equipment and for businesses and industries around the State which utilize computer technology. 


\section{CONCLUSION}

MARC is an exciting and potentially valuable innovative new tool available to the library community, useful to improve both its own internal operations and, more importantly, its service to others. Nonetheless, before extensive meaningful use of MARC will occur, its potential uses must be identified and explored. This article has attempted to give a picture of one such experimental project to improve library service for others within the framework of a particular institution's resources and functions. Much more research is needed on potential and operating uses of MARC and the results of this research need to be disseminated to the library community. In addition, it is the opinion of the authors that for reasons both of available financial resources and expertise much of the research and development with MARC must be a cooperative venture among many different libraries. Some work has been done with MARC cooperatively throughout the country (NELINET (19), OCLC (20), CLSD (21), for example) but much more needs to be done. The future of meaningful uses of MARC is bright; however, much research and development is yet to be done which can best be done as a cooperative effort.

\section{PROGRAMS AND ADDITIONAL INFORMATION}

SDI computer programs and services available from the Department of Libraries to other libraries are described in a publication called "SDI Services and Costs," available from the Oklahoma Department of Libraries, 109 State Capitol, Oklahoma City, Oklahoma 73105. Additional progress reports on the SDI project, as well as other automation projects in Oklahoma are reported in the bi-monthly Oklahoma Department of Libraries Automation Newsletter, which is available on request.

\section{REFERENCES}

1. Cuadra, Carlos A., Editor: Annual Review of Information Science and Technology, 4 (Chicago: Encyclopedia Britannica, 1969), 249-258.

2. Studer, William Joseph: Computer-Based Selective Dissemination of Information (SDI) Service for Faculty Using Library of Congress Machine-Readable Catalog (MARC) Records (Ph.D Dissertation, Graduate Library School, Indiana University, September, 1968), 1.

3. Studer, William J.: "Book-Oriented SDI Service Provided for 40 Faculty." In Avram, Henriette D.: The MARC Pilot Project; Final Report on a Project Sponsored by the Council on Library Resources, Inc. (Washington: Library of Congress, 1968), 180.

4. Cuadra: op. cit., 243-258.

5. Ibid:. 263-270.

6. Bloomfield, Masse: "Current Awareness Publications; An Evaluation," Special Libraries, 60 (October 1969), 514-520. 
7. Bottle, Robert T.: "Title Indexes as Alerting Services in the Chemical and Life Sciences," Journal of the American Society for Information Science, 21 (January-February 1970), 16-21.

8. Brannon, Pam Barney; et al.: "Automated Literature Alerting System," American Documentation, 20 (January 1969), 16-20.

9. Brown, Jack E.: "The CAN/SDI project; The SDI program of Canada's National Science Library," Special Libraries, 60 (October 1969), 501-509.

10. Davis, Charles H.; Hiatt, Peter: "An Automated Current-Awareness Service for Public Libraries," Journal of the American Society for Information Science, 21 (January-February 1970), 29-33.

11. Housman, Edward M.: "Survey of Current Systems for Selective Dissemination of Information (SDI)." In Proceedings of the American Society for Information Science, 6 (Westport, Connecticut: Greenwood Publishing Corporation, 1969), 57-61.

12. Martin, Dohn H.: "MARC Tape as a Selection Tool in the Medical Library," Special Libraries, 61 (April 1970), 190-193.

13. Bierman, Kenneth John; Blue, Betty Jean: "Processing of MARC Tapes for Cooperative Use," Journal of Library Automation, 3 (March 1970), 36-64.

14. RECON Working Task Force: Conversion of Retrospective Catalog Records to Machine-Readable Form; A Study of the Feasibility of a National Bibliographic Service (Washington D.C.: Library of Congress, 1969).

15. Bierman, Kenneth John: "MARC-Oklahoma Data Base Maintenance Project," Oklahoma Department of Libraries Automation Newsletter, 2 (October 1970).

16. Studer, William J.: (Op. cit., note 2), 23-37.

17. Payne, Charles T.; McGee, Robert S.: "Comparisons of LC Proofslip and MARC tape Arrival Dates at the University of Chicago Library," Journal of Library Automation, 3 (June 1970), 115-121.

18. Bierman, Kenneth John: "MARC-Oklahoma Cooperative SDI Project Report No. 1," Oklahoma Department of Libraries Automation Newsletter, 2 (June \& August 1970), 10-14.

19. Nugent, William R.: NELINET: The New England Library Information Network. Paper presented at the International Federation for Information Processing, IFIP Congress 68, Edinburgh, Scotland, August 6, 1968. (Cambridge, Mass: Inforonics, Inc., 1968).

20. Kilgour, Frederick G.: "A Regional Network - Ohio College Library Center" Datamation, 16 (February 1970), 87-89.

21. The Collaborative Library Systems Development Project (CLSD): Chicago-Columbia-Stanford. Unpublished paper presented at the MARC II Special Institute, San Francisco, September 29-30, 1969. 